\title{
Correction to: Microstructure evolution and grain orientation in ITO targets and their effects on the film characteristics
}

Fangsheng Mei ${ }^{1,2}$, Tiechui Yuan ${ }^{1,2, *}$, Ruidi $\mathrm{Li}^{2, *}$, Kai Qin ${ }^{2}$, and Jingwei Huang ${ }^{2}$

${ }^{1}$ Science and Technology on High Strength Structural Materials Laboratory, Central South University, Changsha 410083, People's Republic of China

${ }^{2}$ State Key Laboratory of Powder Metallurgy, Central South University, Changsha 410083, People's Republic of China

Published online:

14 August 2021

(C) Springer Science+Business Media, LLC, part of Springer

Nature 2021

\section{Correction to:}

Journal of Materials Science: Materials

in Electronics (2018) 29:14620-14634

https:/doi.org/10.1007/s10854-018-9598-7

The authors regret that the printed version of the above article contained a number of errors. The correct and final version follows.
The reference number [29] should be marked in the captions of Figs. 1 and 2.

Another declaration should be noted here that Fig. 10a and $\mathrm{c}$ in this work should be referred by Fig. $8 \mathrm{a}$ and $\mathrm{b}$ in the reference [29] in the original article [J. Eur. Ceram. Soc. 38, 521-533 (2018)].

Publisher's Note Springer Nature remains neutral with regard to jurisdictional claims in published maps and institutional affiliations.

The original article can be found online at https:/ / doi.org/10.1007/s10854-018-9598-7.

Address correspondence to E-mail: tiechuiyuan@csu.edu.cn; liruidi@csu.edu.cn 